\title{
Dimensions of lexical coding in Chinese and English
}

\author{
HSUAN-CHIH CHEN and JAMES F. JUOLA \\ University of Kansas, Lawrence, Kansas 66045
}

\begin{abstract}
Phonology and orthography are closely related in some languages, such as English, and they are nearly unrelated in others, such as Chinese. The effects of these differences were assessed in a study of the roles of phonemic, graphemic, and semantic information on lexical coding and memory for Chinese logographs and English words. Some of the stimuli in the two languages were selected such that the natural confounding between phonemic and graphemic information in English was matched in the set of Chinese words used. An initial scaling study indicated that this attempt to equate degree of phonemic-graphemic confounding was successful. A second experiment used a recognition memory task for English and Chinese words with separate subject groups of native speakers of the two languages. Subjects were to select one of a pair of test words that was phonemically, graphemically, or semantically similar to a word on a previously studied list. Differences in the dimensions of lexical coding in memory were demonstrated in significant Stimulus Type by Decision Type interactions in the recognition data. Chinesespeaking subjects responded most rapidly and accurately in the graphemic recognition task, whereas performance was generally equivalent in all three tasks for the English-speaking subjects. Alphabetic and logographic writing systems apparently activate different coding and memory mechanisms such that logographic characters produce significantly more visual information in memory, whereas alphabetic words result in a more integrated code involving visual, phonological, and semantic information.
\end{abstract}

Cognitive psychologists have long been interested in how variations in the format of visual stimulation result in changes in information processing strategies. The question has been viewed from several different perspectives; consequently, a number of related questions have been formed. For example, are words and pictures recognized by different cognitive mechanisms? Do different writing systems require different processing strategies for comprehension? It has been known for a long time that memory capacity is greater for pictures than for words (Haber, 1970; Shepard, 1967; Standing, 1973), which has led to suggestions that pictures and words are coded differently in memory. On the other hand, the effect of orthographic variation on memory coding has not been extensively investigated. Thus, the primary concern of the present study is the effect of different systems of writing on visual coding and memory mechanisms.

We acknowledge the assistance of Rose Hsu in typing all the Chinese stimuli and thank Edwin Martin and David Thissen for assistance with the design and data analysis, respectively. The research reported herein was performed pursuant to Grant NIE77-0010 from the National Institute of Education, Department of Education, to the second author. However, the opinions expressed herein do not necessarily reflect the position or policy of the National Institute of Education, and no official endorsement by the National Institute of Education should be inferred. Requests for reprints should be sent to James F. Juola, Department of Psychology, Fraser Hall, University of Kansas, Lawrence, Kansas 66045.
Writing systems have been classified by Gibson and Levin (1975) into three major categories: (1) logographic characters, which represent lexical morphemes, as in Chinese or Japanese Kanji; (2) syllabic characters, which represent syllables, such as Kana in Japanese; and (3) alphabetic characters, which represent phonemes, as in English. The various writing systems seem to be associated with different degrees of difficulty of learning to read. For example, it has been estimated that at least $15 \%$ of American school children have serious reading difficulties, and in Norway the percentage is about $11 \%$ (Gibson \& Levin, 1975; Vik, 1976). On the other hand, Makita (1968) claimed that dyslexia is highly uncommon in Japan (less than .1\%). Parallel to Makita's report, it has been estimated that fewer than $1 \%$ of school children have reading difficulties in Taiwan, China (Tamopol \& Tarnopol, 1976, p. 3). It is not clear whether these differences are due to definitions of reading difficulties, to cultural factors, or to differences in writing systems. However, since various writing systems present linguistic information in different formats (e.g., morphemes vs. phonemes), it is possible that different processing strategies are needed to recognize and comprehend words written in the different languages.

In general, the hypothesis that reading different types of orthographies activates different processing strategies has been supported. For example, Sasanuma (1975) reported that for Japanese aphasic patients, the ability to use logographic Kanji and phonetic Kana 
can be selectively impaired. Similarly, for normal subjects, a right visual field superiority is generally found for Kana words and a left visual field superiority is generally found for Kanji (Hatta, 1977; Sasanuma, Itoh, Mori, \& Kobayashi, 1977). Parallel to the finding in Japanese, Park and Arbuckle (1977) reported that memory performance for Korean subjects was better for ideographic characters than for phonetic-based characters in free recall and recognition. Thus, Park and Arbuckle (1977) concluded that memory processes can be affected by the writing system in which the words are presented.

Recently, Biederman and Tsao (1979) found that the magnitude of the Stroop interference effect (i.e., the interference found in naming a colored ink when it is used to spell the name of a conflicting color) is much greater in the Chinese version with Chinese subjects than in the English version with American subjects. They concluded that "a reader of English cannot refrain from applying an abstract rule system to the word; a reader of Chinese may not be able to refrain from configurational processing of the ideography" (Biederman \& Tsao, 1979, p. 131). All these data support the notion that reading different types of orthographies activates different processing strategies. These strategies include perceptual encoding operations that result in recognition of the stimulus. Pattern recognition processes might be different for logographic and alphabetic stimuli, and further, differences in how the words are encoded might influence subsequent memory processes. Sasanuma, Itoh, Kobayashi, and Mori (1980) have suggested that logographic writing systems demand a greater dependence on visual strategies than do phonetic-based writing systems, which tend to depend more on phonological strategies. However, the reality of this speculation has not been verified.

The present study investigated the effect of orthographic variation on lexical coding and memory processes. A memory task was used to test retention for different aspects of lexical codes for Chinese logographs and English words. The memory representation for any written language can be coded along three basic dimensions: graphemic, phonemic, and semantic. Differences in coding and memory representation formats for Chinese and English words were measured by subjects' performance in graphemic, phonemic, and semantic recognition tasks. Subjects were asked to study a word list formed by one word from pairs of graphemically, phonemically, or semantically similar words. The other members of each pair were then used in a subsequent recognition task, in which subjects were asked to decide whether they matched one of the studied words in appearance, sound, or meaning. If the processing strategies for Chinese and English are distinctive, then the information stored in memory should be coded in different formats. Specifically, if the dominant processing strategy for Chinese is visual coding and for English is phonological coding, as proposed by Sasanuma et al. (1980), then these memory codes should be differentially emphasized in retaining information about Chinese characters and English words. If, on the contrary, written languages are processed in similar ways regardless of the writing system, then the memory representation for Chinese characters and English words should be the same, resulting in similar patterns of memory performance.

To conduct a cross-cultural comparison, it is essential to equate stimulus properties for both subject groups. In alphabetic writing systems, the graphemic and phonemic properties are closely related, whereas in logographic writing systems, a similar confounding is usually absent. Therefore, when some of the Chinese stimulus pairs were formed, the graphemic and phonemic properties were purposely confounded in an attempt to match the natural confounding in English stimulus pairs. To investigate whether the attempt to equate the degree of confounding for Chinese and English stimuli was successful, an initial scaling study was conducted. The second experiment then investigated the dimensions of lexical coding and memory for Chinese- and Englishspeaking subjects.

\section{EXPERIMENT 1}

Word pairs can be found in both English and Chinese that are nearly identical semantically and yet differ in visual and phonemic properties. Similarly, homophone pairs can be formed that are unrelated visually and semantically. A problem arises with graphemic similarity, however, in that different words cannot be written in exactly the same way for our purposes. Further, graphemically similar pairs tend to be pronounced similarly in English, whereas this is not generally the case in Chinese. The problem becomes one of selecting words that are highly similar visually yet have clearly different pronunciations and meanings in both English and Chinese. Because of the phonemic-graphemic relation in English, words that are spelled similarly tend to be pronounced somewhat alike even if we try to minimize this confounding in the selection of stimuli. Therefore, after the English graphemically similar pairs had been selected, Chinese pairs were selected to match the degree of confounding between sound and spelling that was unavoidably present in the English pairs. The questions raised by these procedures are: (1) are the graphemic pairs of equal visual similarity in English and Chinese?; and (2) is the degree of sound-spelling confounding equated in the word pairs from the two languages? The first experiment addressed these questions.

A visual similarity scaling task was designed to investigate the relative graphemic similarities for both graphemically similar pairs and phonemically similar pairs in Chinese and English. This was done by compar. ing American subjects' judgments for English and 
Chinese pairs and Chinese subjects' judgments for the same pairs. However, in order to compare the scaling performance for the two subject groups, it is essential to partial out possible confoundings, such as how the two groups of subjects use the scale and their relative familiarities with the verbal stimuli. This was done by adding neutral stimuli, random shapes from the Vanderplas and Garvin (1959) study, to the stimulus lists for both groups of subjects. The random shapes not only are unfamiliar to both subject groups but also lack semantic and phonemic properties. Thus they allow relatively pure measurements of how the two subject groups use the visual similarity scale, and they enable a method of adjusting subjects' performance on the verbal stimuli in order to make appropriate crosscultural group comparisons. (A similar technique was used by Biederman and Tsao, 1979.) The adjusted scale values then can be used to judge whether we have succeeded in matching the degree of visual similarity and graphemic-phonemic confounding in Chinese and English stimulus pairs.

\section{Method}

Subjects. Twenty-five native Chinese-speaking and 25 native English-speaking graduate and undergraduate students at the
University of Kansas volunteered to participate. All the Chinese subjects were from Taiwan, China, and had learned English as a second language, and the English subjects were American and were naive to Chinese. All subjects reported normal or correctedto-normal vision.

Stimuli. Figures 1 and 2 contain the complete set of verbal stimuli used in the experiment. ${ }^{1}$ There were six types of stimuli, with 24 pairs of each type. These were the following: (1) English graphemically similar pairs (EGSP)-The words in each pair were spelled the same after the first letter but had different meanings and pronunciations, although the close relationship between orthography and phonology in English produced some phonemic similarity. (2) Chinese graphemically similar pairs (CGSP)-The pairs were formed by characters constructed alike (most characters in each pair differed by only a single stroke), but with different meanings. Further, to match the kind of graphemephoneme confounding in English, characters in each pair were purposely selected to share the same vowel. (3) Similar randomshape pairs (SRSP)-The shapes in each pair were formed by using two identical random shapes and making one of them differ in only a single feature, in an attempt to match visual similarity for the EGSP and CGSP. (4) English phonemically similar pairs (EPSP)-The pairs chosen had maximum phonemic similarity (i.e., they were homophones) with minimum graphemic similarity (i.e., they usually differed in two or more letters or in word length), and they differed in meaning. (5) Chinese phonemically similar pairs (CPSP)-The pairs were homophones, differed in meaning, and were constructed dissimilarly but had the same radical (one of the major components of Chinese logographs), in an attempt to match the grapheme-phoneme con-

\begin{tabular}{|c|c|c|c|c|c|}
\hline \multicolumn{2}{|c|}{ Graphemically SP } & \multicolumn{2}{|c|}{ Phonemically SP } & \multicolumn{2}{|c|}{ Semantically SP } \\
\hline$\mu_{\hat{1}}$ 恰 & 衡 衝 & 訓 訊 & 楆植 & 長 & 满洋 \\
\hline 間 閒 & 娇 桥 & 没洲 & 峖 & 幸祽 & 找 缸 \\
\hline 困因 & 已己 & 莉 菬 & 诞 沿 & 快 速 & 紪 躬 \\
\hline 鳥 島 & 盖 重 & 憾 悍 & 仕 侍 & 跳 躍 & 洲; 小 \\
\hline 怒 恏 & 就軣 & 狀 倠 & 伏俘 & 錯 誤 & 競 寒 \\
\hline 租 粗 & 笨宗 & 任仿 & 站管 & 石岩 & 壽 老 \\
\hline 睛 晴 & 陪 倍 & 吃虽 & 窎窎 & 舵 䐦 & 已 大 \\
\hline 冲 仲 & 胖 拌 & 渤 泊 & 緒 續 & 奇 珍 & 諴 信 \\
\hline 義载 & 彼 披 & 私 栕 & 派 渄 & 說 煐 & 病疫 \\
\hline 芩芩 & 伉 杭 & 治 滞 & 沫 漠 & 真 實 & 共 合 \\
\hline 母 抽 & 湲 暖 & 穌 蔬 & 鐵 秢 & 愁 歖 & 柰 院 \\
\hline 戊战 & 抻 坤 & 吱瓷 & 等江 & 冷 寒 & 㤯㹣 \\
\hline
\end{tabular}

Figure 1. Complete list of Chinese stimuli used in the study. The graphemically and phonemically similar pairs were used in both Experiments 1 and 2; semantically similar pairs were used only in Experiment 2 (SP = similar pairs). 


\begin{tabular}{|c|c|c|c|c|c|c|c|c|c|c|c|}
\hline \multicolumn{2}{|c|}{ (:raphemically } & \multirow{2}{*}{$\frac{\text { Similar }}{\text { wives }}$} & \multirow{2}{*}{$\frac{\text { Pairs }}{\text { gives }}$} & \multicolumn{4}{|c|}{ Phonemically Similar Pairs } & \multicolumn{2}{|c|}{ Semantically } & \multirow{2}{*}{$\frac{\text { Similar }}{\text { error }}$} & \multirow{2}{*}{$\frac{\text { Pairs }}{\text { mistake }}$} \\
\hline patio & ratio & & & sight & cite & dyed & died & sea & ocean & & \\
\hline nature & mature & gather & father & shoot & chute & wring & ring & ache & pain & ship & boat \\
\hline crown & grown & honor & donor & colonel & kernel & billed & build & jump & leap & aged & old \\
\hline plow & blow & bone & gone & weighed & wade & pore & pour & speedy & rapid & trust & believe \\
\hline dull & pull & jury & bury & packed & pact & bale & bail & rock & stone & novel & unique \\
\hline dough & rough & worse & horse & sense & cents & waste & waist & game & sport & chill & cold \\
\hline lower & tower & liver & diver & paws & pause & reign & rain & i11 & sick & luck & fortune \\
\hline clove & glove & demon & lemon & urn & earn & tide & tied & large & nuge & hide & conceal \\
\hline food & hood & wolf & golf & manner & manor & flour & f lower & iittle & small & whole & total \\
\hline new & few & put & nut & two & too & him & hymn & tall & high & fact & truth \\
\hline mint & pint & cash & wash & right & rite & vane & vein & see & $100 \mathrm{k}$ & find & discover \\
\hline home & some & most & lost & days & daze & heir & air & talk & speak & worry & anxiety \\
\hline
\end{tabular}

Figure 2. Complete list of English stimuli used in the study. The graphemically and phonemically similar pairs were used in both Experiments 1 and 2; semantically similar pairs were used only in Experiment 2.

founding in the English phonemically similar pairs. (6) Dissimilar random-shape pairs (DRSP)-The shapes in each pair were formed by modifying one of the two identical random shapes to make them similar in only one feature, to match the relatively low visual similarity for the EPSP and CPSP.

Procedure. Subjects were tested in groups of three to five at a time. All subjects received a booklet that included all six types of stimuli (144 pairs, totally), 12 practice pairs ( 2 pairs for each type of stimulus), and written instructions with six examples and suggested responses. All the experimental stimuli were randomly ordered and listed on 12 separate pages. The pages were then randomly ordered into the 50 different test booklets used. For each pair of stimuli, the subject's task was to judge the visual similarity of the pair and to respond by circling a number along a 7-point scale located under the stimulus pair. In the scale, 1 indicated that the pair members were visually identical and 7 indicated they were completely different. Subjects were encouraged to use all the scale values.

\section{Results and Discussion}

Mean scale values were computed for each cell of the design for each subject. The data are summarized in Table 1.

Differences in usage of the scale between American and Chinese subject groups can be found in the data for the SRSP and DRSP. In both cases, the mean scale values for American subjects were significantly lower than those for Chinese subjects [for SRSP, $t(48)=3.21$, and for DRSP, $t(48)=4.57$; both ps $<.01]$. However, the difference between the judged visual similarities for the SRSP and DRSP was equivalent for the two groups $[t(48)=.38, p>.05]$. Thus, to compare the two subject groups' judgments for the verbal stimuli, an adjustment of the data based on their respective judgments for the random shapes is apparently necessary and appropriate. This was done by taking the difference between the mean judgment for the graphemically similar words and that for the similar shapes and dividing by the standard deviation of the shape data for each group. Adjustments of the data for phonemically similar pairs were made using the data from the DRSP, since they have comparable visual similarity. All the following statistical analyses were conducted on the data so transformed. The transformed data are summarized in Table 2.

Three planned comparisons between the American subjects' performance on English stimuli and Chinese

Table 1

Mean Visual Similarity Scale Values and Standard Deviations Across Stimuli for Each Subject Group and Stimulus Type (Experiment 1)

\begin{tabular}{|c|c|c|c|c|c|c|c|c|c|c|c|c|}
\hline \multirow[b]{3}{*}{ Subject Group } & \multicolumn{12}{|c|}{ Stimulus Type } \\
\hline & \multicolumn{2}{|c|}{ CGSP } & \multicolumn{2}{|c|}{ CPSP } & \multicolumn{2}{|c|}{ EGSP } & \multicolumn{2}{|c|}{ EPSP } & \multicolumn{2}{|c|}{ SRSP } & \multicolumn{2}{|c|}{ DRSP } \\
\hline & Mean & SD & Mean & $\mathrm{SD}$ & Mean & SD & Mean & $\mathrm{SD}$ & Mean & SD & Mean & SD \\
\hline American & 2.91 & .58 & 5.02 & .64 & 2.68 & .15 & 4.42 & .54 & 2.85 & .61 & 5.39 & .71 \\
\hline Chinese & 3.35 & .53 & 5.59 & .51 & 3.92 & .24 & 4.91 & .76 & 3.55 & .88 & 6.19 & .47 \\
\hline
\end{tabular}

Note-Scale values: $1.0=$ visually identical; $7.0=$ maximum visual discrepancy. $C G S P=$ Chinese graphemically similar pairs, $C P S P=$ Chinese phonemically similar pairs; $E G S P=$ English graphemically similar pairs, $E P S P=$ English phonemically similar pairs; $S R S P=$ similar random-shape pairs, DRSP = dissimilar random-shape pairs. 
Table 2

Transformed Mean Visual Similarity Scale Values and Standard Deviations Across Stimuli for Each Subject Group and Word Type (Experiment 1)

\begin{tabular}{|c|c|c|c|c|c|c|c|c|}
\hline \multirow{3}{*}{$\begin{array}{l}\text { Subject } \\
\text { Group }\end{array}$} & \multicolumn{8}{|c|}{ Word Type } \\
\hline & \multicolumn{2}{|c|}{ CGSP } & \multicolumn{2}{|c|}{ CPSP } & \multicolumn{2}{|c|}{ EGSP } & \multicolumn{2}{|c|}{ EPSP } \\
\hline & Mean & SD & Mean & SD & Mean & SD & Mean & SD \\
\hline $\begin{array}{l}\text { American } \\
\text { Chinese }\end{array}$ & $\begin{array}{r}.10 \\
-.23\end{array}$ & $\begin{array}{l}.96 \\
.60\end{array}$ & $\begin{array}{l}-.52 \\
-1.28\end{array}$ & $\begin{array}{r}.90 \\
1.07\end{array}$ & $\begin{array}{r}-.28 \\
.42\end{array}$ & $\begin{array}{l}.25 \\
.27\end{array}$ & $\begin{array}{l}-1.36 \\
-2.72\end{array}$ & $\begin{array}{r}.75 \\
1.61\end{array}$ \\
\hline
\end{tabular}

Note-CGSP $=$ Chinese graphemically similar pairs, $C P S P=$ Chinese phonemically similar pairs; $E G S P=$ English graphemically similar pairs, EPSP $=$ English phonemically similar pairs.

subjects' performance on Chinese stimuli were made. No significant differences were found between the mean scale values for American subjects on EGSP and that for Chinese subjects on CGSP [t $(48)=.43, p>.05$ ] or between the mean scale values for American subjects on EPSP and that for Chinese subjects on CPSP [t $(48)=$ $.31, \mathrm{p}>.05]$. Further, the difference between mean values for EGSP and EPSP for American subjects was similar to that for CGSP and CPSP for Chinese subjects $[t(48)=1.41, p>.05]$. These results indicated that the judged visual similarity of the graphemically similar pairs was equivalent for Chinese and American subjects when they judged words from their native languages. Thus, our attempts to match the degree of graphemephoneme confounding in the two languages was largely successful. Moreover, there were significant differences between visual similarity judgments for EGSP and EPSP within each group [American, $t(24)=6.60$, and Chinese, $t(24)=3.64$; both $p s<.01]$ and for CGSP and CPSP [American, $\mathrm{t}(24)=2.30$, and Chinese, $\mathrm{t}(24)=$ 4.20 ; both ps $<.05$ ] . Clearly, the relative visual similarity for graphemically similar pairs was significantly greater than that for phonemically similar pairs in both languages.

\section{EXPERIMENT 2}

The results of Experiment 1 indicated that the relative visual similarity for graphemically similar pairs and the degree of graphemic confounding in phonemically similar pairs were highly comparable in the selected Chinese and English word pairs. Since other properties for Chinese and English stimuli were already equated (i.e., all the Chinese and English phonemically similar pairs were formed by homophones, semantically similar pairs were formed by synonyms, and all the Chinese semantically similar pairs were directly translated from English synonym pairs), we can proceed with reasonable confidence to the study of memory representations for Chinese characters and English words under the assumption that there are no serious problems in balancing the coding dimensions between the two written languages.
The second experiment made use of a memory task for a list of words presented one at a time. Three types of specially designed recognition tests were given to investigate the dimensions of lexical coding for Chinese and English words. In each test trial, two words were simultaneously presented, but neither was identical to one of the previously studied words. Rather, to assess memory representation of the previously studied words along graphemic, phonemic, and semantic dimensions, only one of those properties of a test item matched that of the studied word. The other item of the test pair did not match a previously studied word on any dimension. In both immediate and 24-h delayed test sessions, subjects had to use graphemic, phonemic, or semantic criteria to make recognition responses.

\section{Method}

Subjects. One native Chinese-speaking and 24 native Englishspeaking undergraduates participated for research credit in an introductory psychology class at the University of Kansas. Twenty-three native Chinese-speaking graduate students at the University of Kansas received $\$ 3$ for their participation. All 24 Chinese subjects had completed their bachelor's degrees in Taiwan (15 of them had been in the U.S. for less than 6 months). All 48 subjects were right-handed and had normal or corrected-to-normal vision. None of them had participated in the first experiment.

Stimuli. The stimuli were 24 examples of each of six types of word pairs (see Figures 1 and 2). The Chinese and English graphemically similar and phonemically similar pairs were the same as those used in Experiment 1. In addition, there were two more stimulus pairs: (1) English semantically similar pairs-The words in each pair were synonyms and were visually and phonemically dissimilar. ${ }^{2}$ (2) Chinese semantically similar pairs-All the pairs were translated directly from the English semantically similar pairs; the words in each pair were also synonyms and were visually and phonemically dissimilar. ${ }^{3}$

A thorough counterbalancing scheme was used to insure that all words were used equally often in each cell of the experimental design. For illustration, let us first consider the 24 English word pairs in each of the three similarity groups. These were randomly divided in half and then collected into two groups, each containing 12 graphemically similar, 12 phonemically similar, and 12 semantically similar pairs. Each of the word pairs in these groups was then divided, resulting in four different lists of 36 single words each. Each of these lists was used as a study list for groups of 12 different subjects, and the list of matching pairs appropriate to the study list was used to provide targets in the recognition decision task. Six words of each type were selected for the immediate test and six were chosen for the delayed test for half of the subjects studying any particular list, and the immediate and delayed test items were reversed for the other half. Words for the distractor items used in the recognition task were selected from the lists of nonmatching word pairs. The unrelated words paired for the recognition test were matched as closely as possible to the matching words in word length and word frequency and for the original similarity groups to which they belonged. This procedure was then repeated for the Chinese stimuli.

Stimulus words for the study lists were typed onto slide transparencies using an IBM Selectric typewriter for English stimuli and a NIKKEI Chinese typewriter for Chinese stimuli. The slides were projected by a Kodak Carousel slide projector on to a DA-LITE movie screen placed about $2.8 \mathrm{~m}$ in front of the subject. Stimulus pairs for the test phases were typed on white paper and then photoenlarged to twice their normal 
size for English and thrice their normal size for Chinese, and they were adhered to $15.2 \times 22.9 \mathrm{~cm}$ white cards for presentation in an Iconix three-field tachistoscope. The horizontal visual angle for English test pairs as they appeared in the tachistoscope was about 3.2-4.2 deg (depending on word length), and that for Chinese pairs was about $3.2 \mathrm{deg}$.

Procedure. All subjects were run individually in two $30-\mathrm{min}$ sessions. Subjects received instructions and stimuli in their native languages only. Subjects in each group were randomly assigned to receive one of the 36 -word lists presented at a rate of $8 \mathrm{sec} /$ word, followed by the immediate Iecognition decision tests. Twenty-four hours later, a delayed recognition test was given to each subject.

In the presentation phase, subjects were instructed to concentrate on each word as it was presented in preparation for a later memory test. During the immediate test phase, each subject received three types of recognition decision tests (six trials in each type of test). These tests included graphemic, phonemic, and semantic recognition decisions. The order of the different types of tests was balanced across subjects. Each type of test was preceded by instructions indicating the type of decision to be made, and two practice trials were given. In the test phase, the subject's task was to use the given criterion (i.e., graphemic, phonemic, or semantic) to decide which of the items in the test pair was similar to a word in the previously studied list and to respond by pushing the corresponding button (left or right) to indicate its position. The instructions emphasized that accuracy rather than speed was important, but both were measured. At the end of the immediate test session, the subjects were instructed to come back $24 \mathrm{~h}$ later; however, no specific information about what they would do on the 2 nd day was given to them. When subjects came back the 2nd day, the delayed test was given to them. During the delayed test phase, the subjects' task, the procedure, and the order of the three types of tests were the same as on the immediate test; however, all the words in each type of test were new. That is, the word pairs had notbeen tested in the immediate test session.

\section{Results}

Error proportions and mean response times for correct responses were computed for each cell of the design for each subject. The data for Experiment 2 are presented in Figure 3 , which presents the mean error proportions as functions of stimulus type, time of test, and decision type, and Figure 4 presents the response time data.

The arcsin-transformed error proportions and the logtransformed mean response times were analyzed using separate analyses of variance with one between-subjects variable (stimulus type: Chinese vs. English) and two within-subjects variables (time of test: immediate vs. 24-h delayed; and decision type: graphemic, phonemic, or semantic). The arcsin-transformed error proportions and $\log$-transformed mean response times are presented in Table 3.

In the error proportions analysis, significant main effects were found for stimulus type $[F(1,46)=4.91$, $\mathrm{p}<.05]$ and for decision type $[\mathrm{F}(2,92)=8.49, \mathrm{p}<.001]$. As shown in Figure 3, those effects were completely due to the highly accurate graphemic decisions for Chinese stimuli. The effect of time of test was marginally significant $[F(1,46)=3.16, p<.09]$, indicating that fewer errors were made in the immediate test session than in the delayed test session. The main result was the significant interaction between stimulus type and decision type $[F(2,92)=19.86, p<.0001]$. When the data for English and Chinese were examined separately, it was found that there were no significant results for English. For Chinese, the responses for graphemic decisions were more accurate than both the phonemic and semantic decision responses [phonemic vs. graphemic, $\mathrm{t}(23)=6.35$, and semantic vs. graphemic, $\mathrm{t}(23)=$ 4.50 ; both ps $<.0001]$.

Separate analyses were performed on the logtransformed reaction time data, and all the main effects were significant [stimulus type, $F(1,46)=15.84$, time of test, $F(1,46)=5.24$, and decision type, $F(2,92)=10.38$; all ps $<.05]$. Similar to the error proportions analyses, the Stimulus by Decision interaction was significant $[F(2,92)=35.92, p<.0001]$. Further, the response times for graphemic decisions were shortest for Chinese subjects [phonemic vs. graphemic, $\mathrm{t}(23)=7.04$, and semantic vs. graphemic, $\mathrm{t}(23)=5.04$; both ps $<.001]$. The graphemic decisions were slowest for American subjects [phonemic vs. graphemic, $t(23)=2.58$, and semantic vs. graphemic, $t(23)=4.20$; both $\mathrm{ps}<.01$ ] . No other effects were significant.

\section{Discussion}

Since different writing systems differ in their relationships to the spoken language, it is essential to find out whether readers of different writing systems require different processing strategies in order to read efficiently. The present experiment considers the issue from the perspective of lexical coding and memory mechanisms. It is believed that the pattern of memory representations not only reflects whether the various writing systems activate different processing strategies but also specifies some of the differences between alternative processes. The results demonstrated that the format of coding and memory representations for logographic Chinese and alphabetic English are different, a fact reflected by significant Stimulus Type by Decision Type interactions in both the error proportions and reaction time data. In Chinese, subjects could more accurately and rapidly respond in the graphemic recognition task than in any other kind of task. A quick review of the important construction features for Chinese logographs will make the results easy to understand. There are thousands of logographic characters, each of them expressing a single particular morpheme. The logographs are made up of strokes. Strokes can be combined to make up radicals, which are one of the basic components for most Chinese logographs, and sometimes these radicals are meaningful, in that they give a hint about the general meaning of a character. All the logographic characters are monosyllables, and generally, there is no constant and reliable symbol-to-sound correspondence. The number of characters and their monosyllabic nature create a special feature for logographic Chinese; that is, the language has a large number of homophones. Thus, the phonemic 


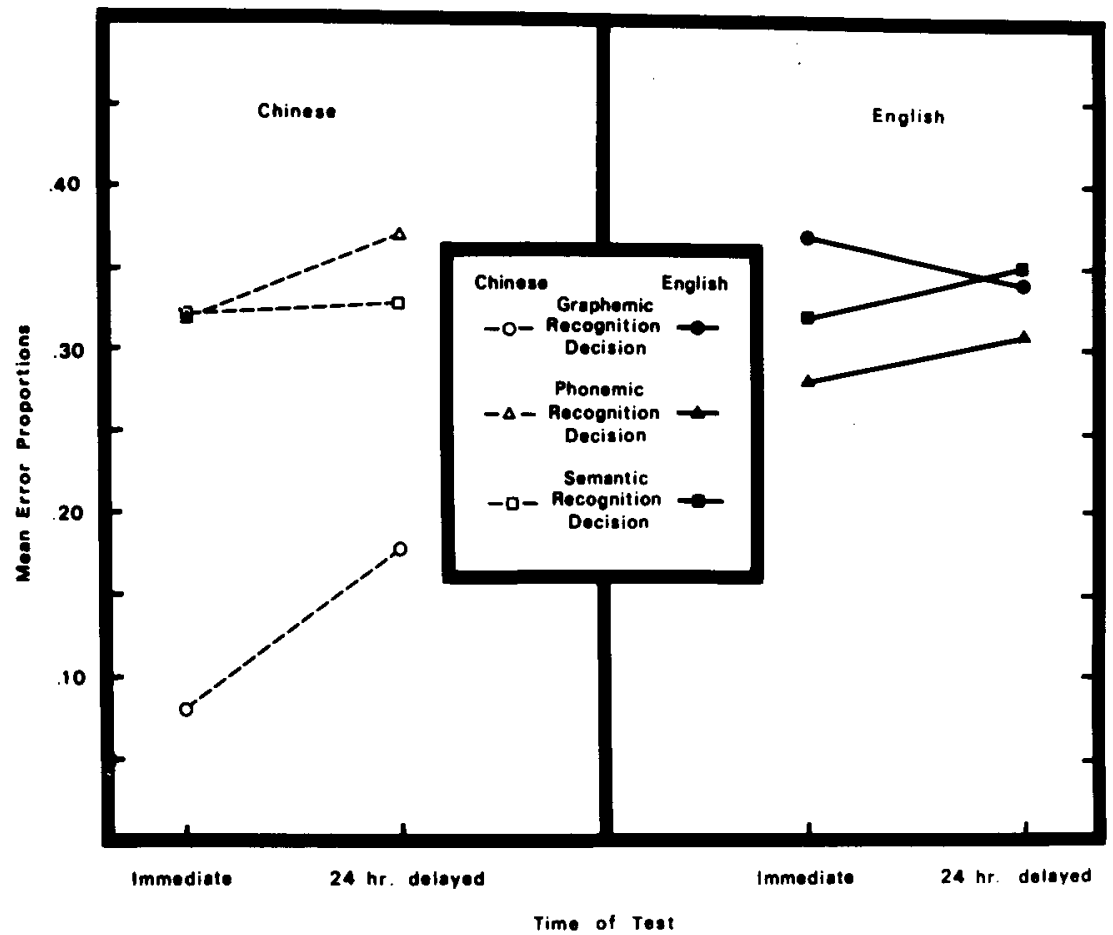

Figure 3. Mean error proportions for graphemic, phonemic, and semantic recognition decisions plotted against time of test for Chinese and English stimuli (Experiment 2).

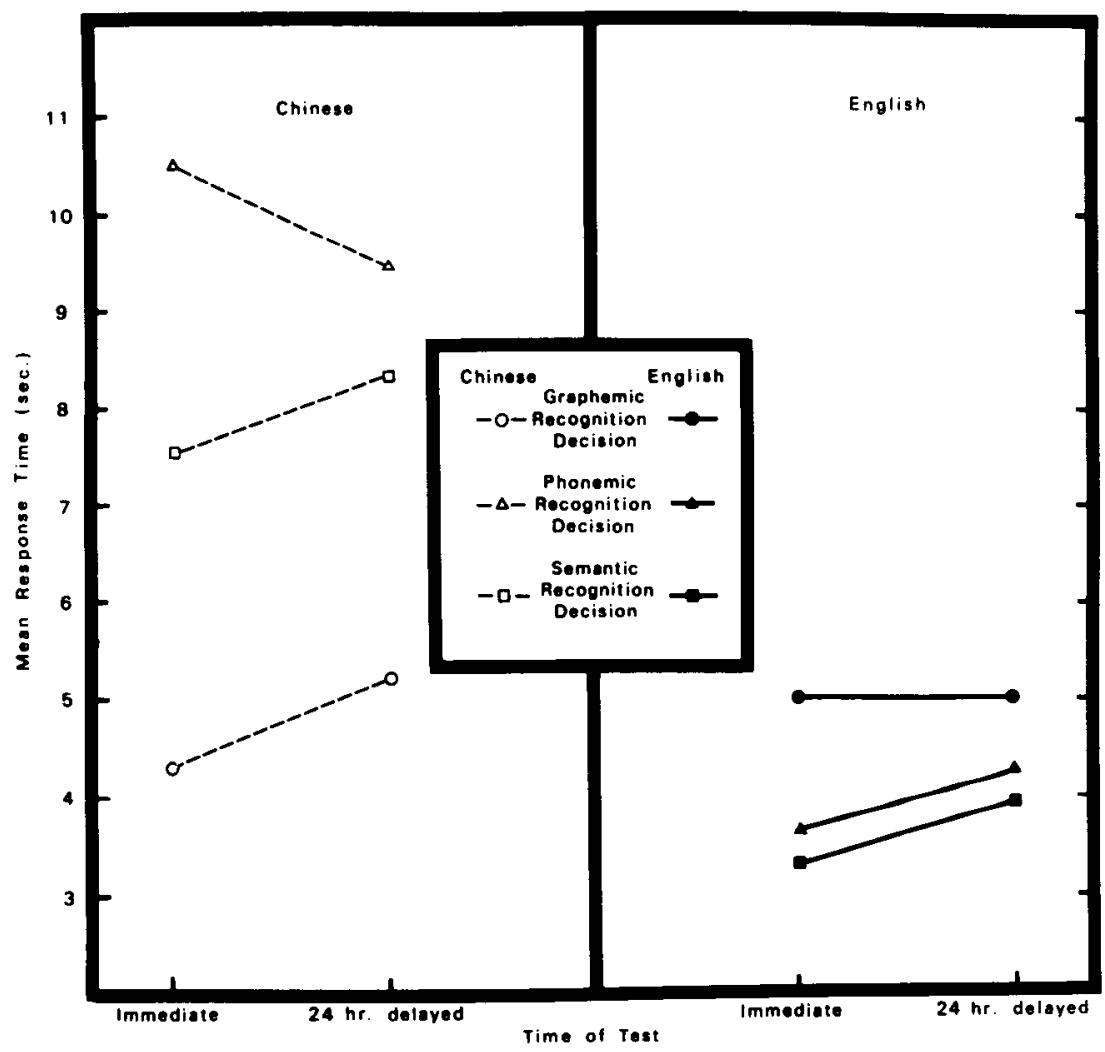

Figure 4. Mean response times (in seconds) for graphemic, phonemic, and semantic recognition decisions plotted against time of test for Chinese and English stimuli (Experiment 2). 
Table 3

Mean Arcsin-Transformed Error Proportions (EP) and

Log-Transformed Response Times (RT) for Each Stimulus Type, Time of Test, and Test Type (Experiment 2)

\begin{tabular}{lccccc}
\hline & \multicolumn{4}{c}{ Stimulus Type } \\
\cline { 2 - 5 } \multicolumn{1}{c}{ Test Type } & EP & RT & & EP & RT \\
\cline { 2 - 5 } \cline { 5 - 6 } & & \multicolumn{3}{c}{ Immediate Test } \\
Graphemic Recognition & .17 & .53 & .63 & .63 \\
Phonemic Recognition & .56 & .91 & .50 & .52 \\
Semantic Recognition & .57 & .82 & .54 & .49 \\
& & & Delayed & Test & \\
Graphemic Recognition & .36 & .68 & .59 & .63 \\
Phonemic Recognition & .64 & .90 & .55 & .59 \\
Semantic Recognition & .58 & .86 & .61 & .54 \\
\hline
\end{tabular}

representations of logographs are probably less distinctive than their visual representations. Furthermore, the visual aspects of each character are particularly important, not only in terms of helping to differentiate and identify a character among others, but also in providing information about the general meaning of the character. This is probably why the results suggest that logographic characters heavily activate "visual" encoding strategies, resulting in emphasis on visual codes in memory, whereas phonological recognition and memory processes based on phonological codes are deemphasized. It is, then, no surprise that the visual mode is superior to the auditory mode in memory for Chinese logographs, whereas the result is opposite for English (Turnage \& McGinnies, 1973).

For the English stimuli, there is evidence that performance for the graphemic recognition task tended to be slower than the others. However, no significant results were found for the error proportions data. When compared with the data for Chinese logographs, the visual representation is relatively less important in English than are the phonemic and semantic representations in the memory task used in Experiment 2. Further, since performance in none of the three types of tasks was highly distinctive, it seems that an integrated coding strategy involving visual, phonological, and semantic information contributes to memory for English words. Thus, as Davelaar, Coltheart, Besner, and Jonasson (1978) have pointed out, models based solely on either graphemic or phonemic encoding are unable to account for all the lexical access data for English words.

The results of Experiment 2 demonstrated that lexical coding and memory formats for Chinese and English words are different. Alphabetic and logographic writing systems apparently activate different processing strategies, resulting in different visual encoding processes and subsequent memory codes. A similar suggestion has been raised by previous researchers of various topics: in writing systems and reading (Hung \& Tzeng, in press), in visual half-field recognition studies (Sasanuma et al., 1977,1980 ), in word recognition and recall (Park \& Arbuckle, 1977), in aphasia studies (Sasanuma, 1975), and in the Stroop effect (Biederman \& Tsao, 1979). Furthermore, the present research demonstrated that visual representation plays a significant role in memory for Chinese logographs. It seems to suggest that perception and memory for logographs depend more on purely visual processes than is the case for alphabetic writings. On the other hand, no strong evidence was found to support the notion that memory for English words depends more on phonemic codes than on visual or semantic codes. It seems that English activates a more integrated processing mechanism. However, studies conducted by Hung, Tzeng, and their associates have shown that phonetic recoding occurs in more complex information processing tasks in Chinese (e.g., in the recognition of multiple-character stimuli and in reading). Such processes are apparently more similar for logographic Chinese and alphabetic English (for a review, see Tzeng \& Hung, 1980). It is possible that in later stages of information processing, such as parsing and integration, and for the more complex information processing tasks, such as reading for comprehension, cognitive processes are more similar and relatively independent of the type of orthography.

\section{REFERENCES}

Biederman, I., \& Tsao, Y. C. On processing Chinese ideographs and English words: Some implications from Stroop-test results. Cognitive Psychology, 1979, 11, 125-132.

Chapman, T. L. Roget's international thesaurus (4th ed.). New York: Crowell, 1977.

Davelaar, E., Coltheart, M., Besner, D., \& Jonasson, J. T. Phonological recoding and lexical access. Memory \& Cognition, 1978, 6, 391-402.

Gibson, E. J., \& Levin, H. The psychology of reading. Cambridge, Mass: M.I.T. Press, 1975.

HABER, R. N. How we remember what we see. Scientific American, 1970, 222, 104-112.

HatTA, T. Recognition of Japanese Kanji in the left and right visual field. Neuropsychologia, 1977, 15, 685-688.

Hung, D. L., \& Tzeng, O. J. L. Orthographic variations and visual information processing. Psychological Bulletin, in press.

Juola, J. F., Fischler, I., Wood, C. T., \& Atrinson, R. C. Recognition time for information stored in long-term memory. Perception \& Psychophysics, 1971, 10, 8-14.

Kučera, H., \& Francis, W. H. Computational analysis of present-day American English. Providence, R.I: Brown University Press, 1967.

MaKitA, $K$. The rarity of reading disability in Japanese children. American Journal of Orthopsychiatry, 1968, 38, 599-614.

Meyer, D. E., Schvaneveldt, R. W., \& Ruddy, M. G. Functions of graphemic and phonemic codes in visual wordrecognition. Memory \& Cognition, 1974, 2, 309-321.

National Institute for Compilation and Translation. $A$ study on the high frequency words used in Chinese elementary school reading materials. Taipei: Chung Hwa, 1967. 
Park, S., \& Arbuckle, T. Y. Ideograms versus alphabets: Effects of scripts on memory in "biscriptual" Korean subjects. Journal of Experimental Psychology: Human Learning and Memory, $1977,3,631-642$.

Sasanuma, S. Kana and Kanji processing in Japanese aphasics. Brain and Language, 1975, 2, 369-383.

Sasanuma, S., Iтoh, M., Кobayashi, Y., \& Mori, K. The nature of the task-stimulus interaction in the tachistoscopic recognition of Kana and Kanji words. Brain and Language, 1980, 9, 298306.

Sasanuma, S., Itoh, M., Mori, K., \& Kobayashi, Y. Tachistoscopic recognition of Kana and Kanji words. Neuropsychologia, $1977,15,547-553$.

Shepard, R. N. Recognition memory for words, sentences, and pictures. Journal of Verbal Learning and Verbal Behavior, $1967,6,156-163$.

Standing, L. Learning 10,000 pictures. Quarterly Journal of Experimental Psychology, 1973, 25, 207-222.

TARNOPOL, L., \& TARNOPOL, M. Reading and learning problems worldwide. In L. Tarnopol \& M. Tarnopol (Eds.), Reading disabilities: An international perspective. Baltimore, Md: University Park Press, 1976.

Turnage, T. W., \& McGinnies, E. A cross-cultural comparison of the effects of presentation mode and meaningfulness in shortterm recall. American Journal of Psychology, 1973, 86, 869881.

Tzeng, O. J. L., \& Hung, D. L. Reading in a nonalphabetic writing system: Some experimental studies. In J. F. Kavanagh \& R. L. Venezky (Eds.), Orthography, reading and dyslexia. Baltimore, Md: University Park Press, 1980.

VANDE RPLAS, J. M., \& Garvin, E. A. The association value of random shapes. Journal of Experimental Psychology, 1959, 57, 147-154.
VıK, G. H. Reading disabilities in Norwegian elementary grades. In L. Tarnopol \& M. Tarnopol (Eds.), Reading disabilities: An international perspective. Baltimore, Md: University Park Press, 1976.

\section{NOTES}

1. All the English graphemically and phonemically similar pairs were taken from the appendices of Davelaar, Coltheart, Besner, and Jonasson (1978), Juola, Fischler, Wood, and Atkinson (1971), and Meyer, Schvaneveldt, and Ruddy (1974), whereas all the Chinese material were generated by the first author. The mean word frequencies for words used in English graphemically similar and phonemically similar pairs were about 167 and 153 per million words (Kucera \& Francis, 1967), whereas those for Chinese graphemically similar and phonemically similar pairs were about 231 and 201 per million words (National Institute for Compilation and Translation, 1967). All the random shapes were taken from the table for 8-and 12-point random shapes of Vanderplas and Garvin (1959).

2. Part of the English synonyms came from the appendix of Juola et al. (1971), and others were generated by the first author with the help of a thesaurus by Chapman (1977). The mean word frequency of the English synonym pairs was 169 per million words (KuCera \& Francis, 1967).

3. The mean word frequency for the Chinese synonym pairs was about 739 per million words (National Institute for Compilation and Translation, 1967).

(Received for publication May 1, 1981; revision accepted November 10,1981.) 